\title{
EFFECTS OF STRYCHNINE ON THE INTRA- CELLULAR POTENTIALS OF SPINAL MOTONEURONS OF THE TOAD
}

\author{
MOTOY KUNO* \\ Department of Physiology, Faculty of Medicine, Kyoto University, Kyoto
}

\begin{abstract}
An enhancement in the spinal reflex under administration of strychnine is characterized by the motor bursts associated with signs of slow depolarization of spinal motoneurons $(5,14)$. This slow depolarization has been attributed to a direct action of strychnine on the soma membrane, and a close relationship with hyperactivity created by the drug has been suggested (5). Since such a suggestion has been offered by indirect observations, it would be required to use a more direct method in order to decide the site of action of strychnine.

In the present study the response of spinal motoneurons to strychnine was directly recorded with intracellular electrodes. This direct observation has indicated that the slow depolarization of motoneurons results from synaptic transmission but not from the depolarizing action of the drug on the soma membrane. The present study has also demonstrated the characteristics of the action of strychnine on the spinal cord from its initial stage to the final, tetanus, stage. Based on these findings, three stages on the action of the drug can be distinguished according to the doses of strychnine given or to the periods of time elapsed after its injection.
\end{abstract}

\section{METHODS}

The spinal cord of the toad was exposed, and the toad was firmly suspended in a metal frame by clamps fixed on the transverse processes of the vertebral column. The intracellular electrode filled with $3 \mathrm{M}-\mathrm{KCl}$ solution was inserted into a spinal motoneuron from the dorsal or dorsolateral surface of the spinal cord at the level of the 9th or 10th roots under incomplete curarization. The 9th and 10th dorsal and ventral roots were cut and prepared for stimulation. On occasion all the dorsal roots were kept intact, and orthodromic volleys were given to muscle nerves. The administration of strychnine was made into the heart which was exposed previously in order to prevent the displacement of the microelectrode by the injection. In a few experiments observations were made on the excised spinal cord using the same procedure as that described by Araki et al. (1). The feature of hyperactivity observed in the excised spinal cord was scarcely different from that shown in the intact curarized toad. The potential changes were recorded by means of a balanced

Received for publication November 20, 1956.

* 久野 宗

Present address: Physiological Department, Yamaguchi Medical School, Ube. 
D.C. amplifier and a cathode-ray oscilloscope. The experiments were carried out from January to April, 1956. The room temperature ranged from $8^{\circ} \mathrm{C}$. to $19^{\circ} \mathrm{C}$.

\section{RESULTS}

1. 1st Stage (The release action from the inhibitory process):

It has recently been presented that a small dose of strychnine diminished the inhibitory action in the spinal cord of the cat $(2,7)$. Similar effects could also be observed in the present study. In fig. $1 \mathrm{~A}$, the gastrocnemius afferent volley produced a typical inhibitory hyperpolarization (i.p.s.p.) in a motoneuron. Injection of $0.06 \mathrm{mg}$. strychnine nitrate per $\mathrm{kg}$. rapidly converted this hyperpolarization into a depolarization in response to the same volley. The depolarization converted by strychnine, however, set in by about $2.2 \mathrm{msec}$. earlier than the hyperpolarization did before the injection. The i.p.s.p. could also be obtained by stimulating the dorsal root adjacent to the level from which the recording was going (fig. $1 B$ ). The i.p.s.p. obtained in such a way was similarly converted into a depolarization by strychnine, and a spike potential was often elicited from the converted depolarization (fig. $1 B$ ). As described by Araki et al. (1), the simplest reflex (the monosynaptic) was not recognized in the toad's spinal cord. The latency of onset of the i.p.s.p. was also far longer than that expected from a di-synaptic reflex path. It is, therefore, considered that the i.p.s.p. recorded in toad's spinal motoneurons is always contaminated by some excitatory reflexes. The convertibility of the i.p.s.p. into depolarization may thus result from a depression of the inhibitory process $(2,7)$ and a prominence of the masked excitatory reflex (see Discussion).

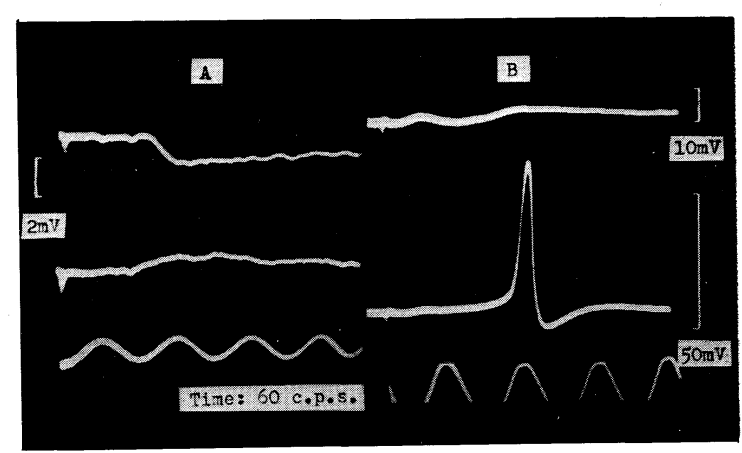

FIG. 1. Intracellular potentials from motoneuron somata. A: Upper trace gives the inhibitory hyperpolarization (i.p.s.p.) produced by a gastrocnemius volley. Lower trace presents the conversion of the above i.p.s.p. into a depolarization by the same stimulus in $50 \mathrm{sec}$. after injection of strychnine nitrate $0.06 \mathrm{mg} / \mathrm{kg}$. $B$ : Upper trace is the i.p.s.p. (apparently contaminated by the excitatory response) produced by stimulating the dorsal root (9th) adjacent to the recording level (10th). Lower trace is the response obtained by the same volley in $70 \mathrm{sec}$. after strychnine injection $0.08 \mathrm{mg} / \mathrm{kg}$. 
In the same period, i.e. in 30 sec. to $1 \mathrm{~min}$. after the toad was given a small dose of strychnine ( 0.05 to $0.1 \mathrm{mg}$. per kg.), a facilitation in the excitatory reflex was observed. As shown in fig. $2 B$, the latent period of the spike potential evoked by a single orthodromic stimulation was shortened by strychnine, and a train of spikes appeared in response to a single stimulus of the same intensity. This repetitive firing occurred at intervals of 14 to 30 msce. Fig. 2 $A$ illustrates the earlier stage of such a facilitatory action. In 30 sec. after giving strychnine, the second synaptic potential was apparently augmented, and this augmented synaptic potential gave rise to the spike potential after an additional $30 \mathrm{sec}$. (fig. $2 A$ ). In these changes it should also be noted that the critical voltage of

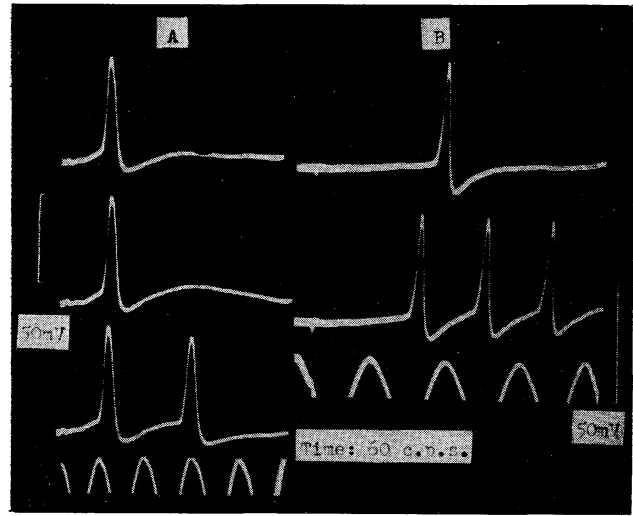

Fig. 2. A: Top record shows a control orthodromic response. The response is slightly augmented in 30 sec. after strychnine injection $0.06 \mathrm{mg} / \mathrm{kg}$. (middle) and two spikes are set up by the same volley after an additional $30 \mathrm{sec}$. (bottom). $B$ : Upper trace is a control orthodromic response. Lower record presents a train of spikes evoked by the same stimulation in $120 \mathrm{sec}$. after strychnine injection $0.03 \mathrm{mg} / \mathrm{kg}$. Note shorter latency of spike potential. the post-synaptic potential (e.p.s.p.)

for generation of the first of a train of spikes was the same as that for the spike potential observed before the injection of strychnine. This may likely suggest that the facilitation is not due to a depolarization of the motoneuron caused by the drug but to an increased presynaptic drive or to an increase in the number of impulses that reach the motoneuron. This suggestion was also supported by the fact that the antidromic response was not at all affected by strychnine (see also fig. 3).

\section{2nd Stage (Long-lasting depolarization with repetitive discharges):}

When the action of strychnine was further advanced, the motoneuron presented a long-lasting depolarization with repetitive discharges superimposed on it, in response to a single orthodromic stimulation (figs. 3 and 4). This slow depolarization was so as large as about 35 to 60 per cent of the first of the superimposed spikes and lasted 80 to $150 \mathrm{msec}$. The amplitude of spike potentials superimposed on the slow wave invariably decreased in the same ratio as the degree of depolarization. The interval of the generation of spikes was quite regular and ranged from 8 to $12 \mathrm{msec}$. It was interesting to note that this slow depolarization was not negated by spike potentials and advanced even during a train of spikes.

When concentrations of strychnine were attained which just failed to produce tetanus spontaneously, it was possible to set up two or three slow de- 


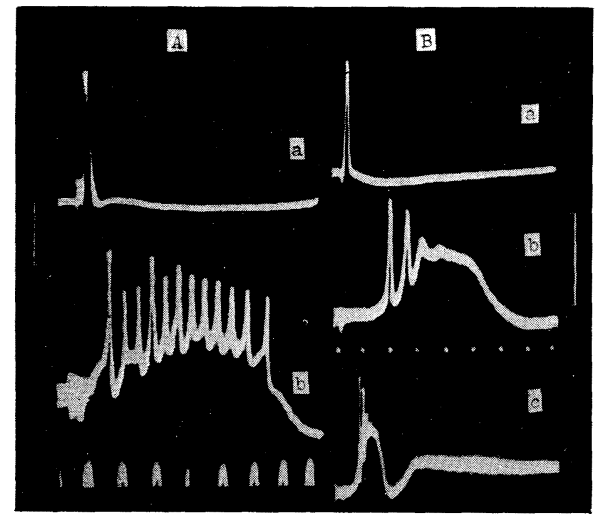

FIG. 3 (left). Changes in intracellular potentials under administration of strychnine. $A$ : Responses in $10 \mathrm{~min}$. after strychnine injection $0.15 \mathrm{mg} / \mathrm{kg}$. Upper record is the antidromic response. Lower record is the orthodromic response. $B$ : Responses of a different motoneuron in $190 \mathrm{~min}$. after strychnine injection $0.2 \mathrm{mg} / \mathrm{kg}$. Top trace is the antidromic response. Middle trace is the orthodromic response. Bottom trace is the same as the middle but with a slower sweep. Time: 60 c.p.s. Voltage scale:

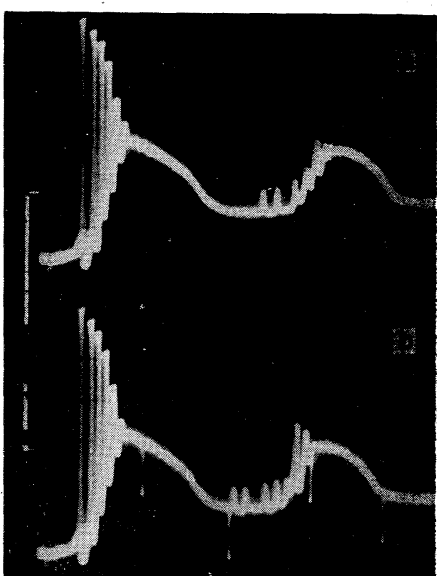

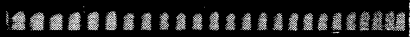

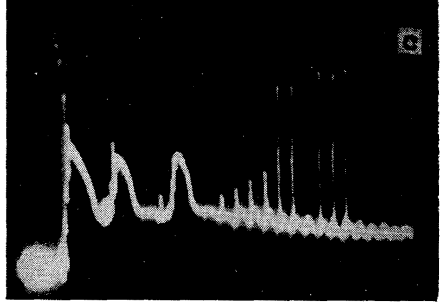
$30 \mathrm{mV}$.

FIG. 4 (right). Changes in the orthodromic response in about $20 \mathrm{~min}$. after administration of strychnine $0.4 \mathrm{mg} / \mathrm{kg}$. $a$ : the response evoked by a single shock. $b$ : the response when stimuli were repetitively given at about $13 /$ sec. $c$ : the same as the above but with a slower sweep. Time: 60 c.p.s. Voltage scale: $50 \mathrm{mV}$.

polarization waves with motor bursts by a single orthodromic shock (fig. $4 a$ ). The slow depolarization produced under such conditions advanced until the amplitude of superimposed spikes was greatly reduced. No spikes was recognized on the falling phase of the depolarization wave, and the responses superimposed on the second wave indicated that the motoneuron had not completely recovered its normal state. The motoneuron probably undergoes the inactivation process during and for a while after such a large depolarization (13). As shown in figs. $4 b$ and $4 c$, these periodic depolarization waves produced by a single shock were little altered by further additional orthodromic stimuli. In fig. $4 c$, there are apparently signs of the arrival of presynaptic bombardments on the motoneuron soma which responds with a small depolarization or occasionally with local responses and single spikes. In general, when an orthodromic stimulus was given in strychnized toad, it took a fairly long time to recover completely, sometimes several minutes. Such a rapid depression of the orthodromic response may be accounted for by a partial exhaustion of some transmitter substance as occurs in the peripheral junction repetitively activated 
$(8,10)$. The response of motoneurons activated orthodromically in strychnized toads may thus be limited by two factors: the inactivation process of motoneurons developing progressively during depolarization built up by successive presynaptic bombardments, and the partial exhaustion of the store of transmitter substance in the presynaptic terminals due to successive impulses which were generated by a single shock.

In fig. $4 c$, not only are there large depolarization waves but also a residual depolarization with slower decay, a half-time being about one second (see also fig. $3 B c$ ). Since the decay is so slow, the residual depolarization may be attributed to a slow diffusion of the cumulate transmitter away from the motoneuron membrane such as occurs in peripheral junction $(8,10)$.

In contrast to such a characteristic feature in the orthodromic response, antidromic volleys evoked the same response of motoneurons as that in the normal state (fig. 3). Even with repetitive antidromic stimulation there was little difference in the action potentials of motoneurons before and after administration of strychnine.

As would be expected in this stage, a single orthodromic volley also set up repetitive firing in a motor axon in the spinal cord (fig. 5). The response of motor axons of strychnized toads, however, was characterized by a much smaller underlying slow depolarization. Even the largest depolarization observed in a case in which the microelectrode was presumed to be in the axon just distal the motoneuron soma, was only a few per cent of the superimposed spikes (fig. $5 a$ ). Usually the underlying slow depolarization was scarcely detectable (fig. $5 b$ ). From this fact it seems reasonable to assume that the large depolarization is restricted to motoneuron cell bodies and spreads electrotonically along motor axons.

Since slight movements of the toad caused by an orthodromic volley were unavoidable under administration of strychnine, it was quite difficult to record the response of the interneuron. Only one interneuron in which internal recording succeeded in strychnized toads showed repetitive discharges in response to a single orthodromic volley. But the frequency of discharges was higher than that of a motoneuron, the interval of spikes being about $4 \mathrm{msec}$., and the discharge lasted for about $50 \mathrm{msec}$.

FIG. 5. Intracellular responses of motor axons evoked by a single orthodromic volley in $10 \mathrm{~min}$. after strychnine injection 0.03 $\mathrm{mg} / \mathrm{kg}$. In $a$, the electrode was presumed to be in the axon just distal to the motoneuron soma. The very low voltage of responses indicates extensive damage both in $a$ and $b$. Time: 60 c.p.s. Voltage scale: 20 $\mathrm{mV}$.

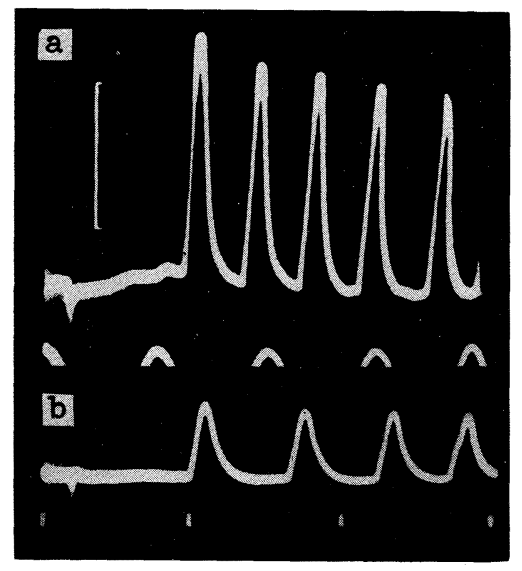




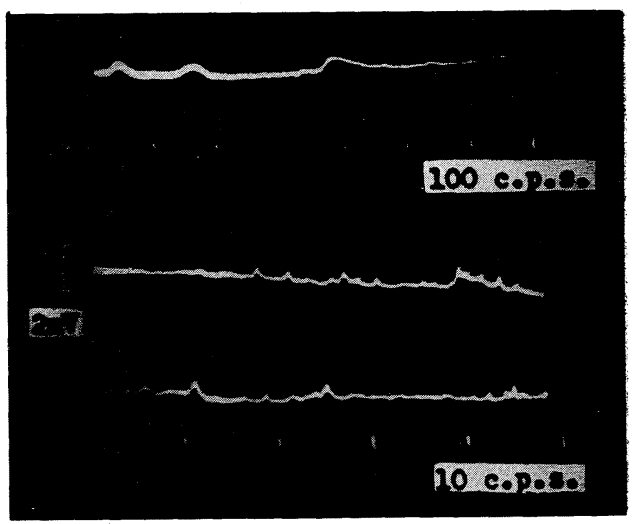

FIG. 6. Spontaneous sub-threshold potentials of motoneurons appeared in $10 \mathrm{~min}$. after injection of strychnine $0.5 \mathrm{mg} / \mathrm{kg}$.
Brock et al. (4) described the spontaneous sub-threshold potentials or synaptic noise in spinal motoneurons of the cat. In motoneurons of the toad no synaptic noise was usually observed under normal conditions. But in 5 to $15 \mathrm{~min}$. after an injection of strychnine, $0.5 \mathrm{mg}$. per kg., spontaneous miniature potentials often (not always) appeared (fig. 6). These potentials were less than 1 $\mathrm{mV}$ in voltage and similar to the post-synaptic potentials in their shape and course. Though no further attempt was made to determine whether the appearance of such a synaptic noise was closely related to the action of strychnine, this

finding would be taken as a sign to indicate the increased activity of presynaptic elements.

\section{3rd Stage (Spontaneous discharge):}

When 0.5 to $1 \mathrm{mg}$. per $\mathrm{kg}$. of strychnine was given, the motoneuron showed an oscillatory discharge beginning suddenly about $15 \mathrm{~min}$. after the injection (fig. 7). This oscillation was quite regular, the cycle being about ten per second, and lasted for several minutes. This stage apparently corresponds to

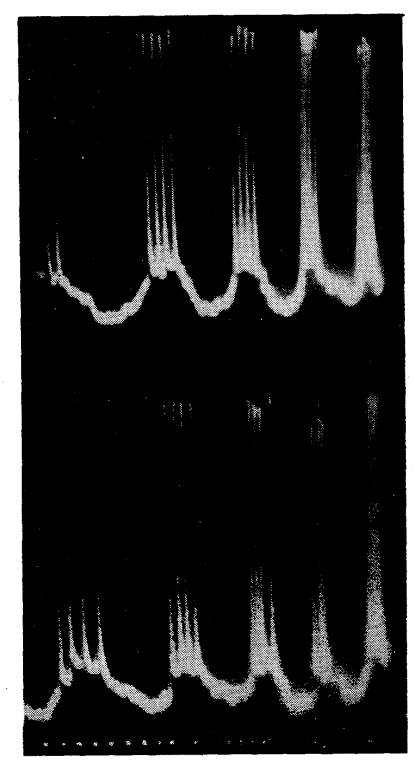
the so-called strychnine tetanus or the stage producing periodic discharge in the ventral root $(3,5,14)$. Usually this spontaneous periodic discharge was not observed when orthodromic volleys were often given after the administration of strychnine. The present study is not in the position to comment on the origin and nature of this periodic activity. It should be noted, however, that the periodic depolarization waves were never negated by superimposed spikes (fig. 7), as was true regarding the slow depolarization in the second stage (figs. 3 and 4). This seems to indicate that such a periodic discharge is set up by the arrival of presynaptic bombardments. In fact, as shown in fig, 7, a

FIG. 7. Spontaneous periodic discharge of motoneurons began suddenly $15 \mathrm{~min}$. after injection of strychnine $0.5 \mathrm{mg} / \mathrm{kg}$. Time: 60 c.p.s. 
number of sub-threshold potentials or synaptic noises could often be detected on the oscillation wave.

\section{DISCUSSION}

For investigating the effect of strychnine on functionally specific synapses or on a simple reflex, the toad has the disadvantage that the motoneuron cannot be fired monosynaptically (1). For this reason, the response of a toad's motoneuron activated orthodromically, even by a muscle afferent volley, should be compared with that of a cat's motoneuron activated by cutaneous volleys which may produce the mixed excitatory and inhibitory action on motoneurons $(9,12)$. The convertibility of the i.p.s.p. into depolarization by strychnine observed in the present study may thus result from a depression of the inhibitory preocess $(2,7)$ and a prominence of the masked excitatory reflex. This release action of strychnine from the inhibitory process may also cause a complex reflex generating a train of spike potentials in the motoneuron, and probably in the interneuron also (see Results 2), in response to a single orthodromic volley (1st Stage). In this stage, when the action of strychnine advances further, a single orthodromic volley would subject the motoneuron to repetitive bombardments at very high frequency by a great number of impulses of presynaptic fibers which make contact with almost the whole surface of the motoneuron soma. The temporally and spatially summated bombardments in the motoneuron may result in an abnormally large depolarization (2nd Stage). This large depolarization which is indestructible by superimposed spikes is well intelligible if successive bombardments are assumed to arrive within the active phase of the e.p.s.p. evoked by the preceding bombardment. The neuronal membrane of the motoneuron will then continuously undergo a nonselective increase in permeability toward all ions; in other words, it will be continuously short-circuited (6) for a considerable period (20 to $40 \mathrm{msec}$.). Actually the superimposed spike potentials gradually decreased in amplitude corresponding to the degree of depolarization (fig. 4). This finding provides support for the short-circuit hypothesis in the e.p.s.p. (6).

The characteristic feature in strychnized preparation was restricted to the orthodromic response only. There was no other sign to suggest the existence of a depolarizing action of the drug on the motoneuron soma itself; neither the increase in the safety factor for the axon-soma conduction, nor lowering of the critical level of the e.p.s.p. for generation of the spike potential in the orthodromic transmission has been observed. Hence, the assumption that the primary action of strychnine is to depolarize all the neurons in the spinal cord (5) does not seem convincing.

The present experiment also showed that the slow depolarization of motoneurons set up by orthodromic volley is restricted to the motoneuron soma and was scarcely recognizable in the motor axon. This is satisfactorily explained by the assumption that a large slow depolarization is built up by repetitive presynaptic bombardments on motoneuron somata and spreads electrotonically along motor axons.

A similar explanation would be applied to the periodic slow depolarization 
with superimposed spikes in the 3rd stage. Actually Frank and Fuortes (11) have recently reported that spontaneous discharge observed in strychnized cats (which corresponds to the 3rd stage in the present results) was accompanied by a large slow depolarization only in cell bodies but not in axons in the spinal cord. It seems likely, that the periodic discharge of motoneurons in strychnine tetanus (3rd Stage) originates in some presynaptic elements but not in motoneurons themselves (14). In supporting this conclusion, the periodic slow depolarization revealed to be indestructible by superimposed spikes. If the rhythmical discharge originates in motoneuron somata, each superimposed spike should negate the preceding slow depolarization, just as shown in repetitive firing produced by constant currents applied directly to the motoneuron (unpublished). But this was not the case in strychnine tetanus. Presumably some presynaptic elements undergo synchronously the periodic excitation in the 3rd stage. Further study on the effect of strychnine on interneurons would be required.

\section{SUMMARY}

Effects of strychnine on spinal motoneurons of the toad were observed with intracellular electrodes. The action of the drug was classified into three stages depending on the dose of the drug or the period of time elapsed after its injection. In the 1st stage, it was found that strychnine depressed the inhibitory process and generated a train ot spikes by a single orthodromic stimulation. In the second stage an orthodromic volley produced a long-lasting depolarization with superimposed spikes which became successively smaller in amplitude corresponding to the degree of depolarization. In the third stage the motoneuron soma spontaneously presented a periodic discharge accompanied by a large depolarization wave. This periodic depolarization wave was not also negated by superimposed spikes. The site of action of strychnine was discussed with the conclusion that the primary action of the drug is to depress the inhibitory process in the spinal cord and that the periodic discharge of motoneurons in strychnine tetanus originates in presynaptic elements.

The author wishes to thank Prof. T. Otani, Kyoto University, for his helpful advice during the present study. The author's thanks are also due to Prof. A. Inouye, Yamaguchi Medical School, for reading this manuscript.

\section{REFERENCES}

1. Araki, T., Otani, T. and Furukawa, T. Jap. J. Physiol. 3: 254, 1953.

2. Bradley, K., EAston, D. M. AND Eccles, J. C. J. Physiol. 122: 462, 1953.

3. BRemer, F. Some problems in Neurophysiolgy. London: Athlone, 1953.

4. BRock, L. G., Coombs, J. S. AND Eccles, J. C. J. Physiol. 117: 431, 1952.

5. Brooks, C. MCC. AND Fuortes, M. G. F. J. Neurophysiol. 15: 257, 1952.

6. CoOmBS, J. S., Eccles, J. C. AND FATT, P. J. Physiol. 130: 374, 1955.

7. Coombs, J. S., Eccles, J. C. AND FAtT, P. J. Physiol. 130: 396, 1955.

8. ECCles, J. C. Ann. Rev. Physiol. 10: 93, 1948.

9. ECCLES, J. C. The neurophysiological basis of Mind. Oxford: Clarendon, 1953. 
10. ECCles, J. C. AND Macfarlane, W. V. J. Neurophysiol. 12: 59, 1949.

11. Frank, K. AND Fuortes, M. G. F. J. Physiol. 130: 625, 1955.

12. Hagbarth, K. E. Acta Physiol. Scand. 26: suppl. 94: 1, 1952.

13. Hodgkin, A. L. ANd Huxley, A. F. J. Physiol. 116: 497, 1952.

14. KoIzumi, K. Amer. J. Physiol. 183: 35, 1955. 